\title{
Introduction of Bifunctional Group onto MWNT by Radiation-Induced Graft Polymerization and Its Use as Biosensor-Supporting Materials
}

\author{
Yu-Jin Lee, ${ }^{1}$ Da-Jung Chung, ${ }^{1}$ Sang-Hyub Oh, ${ }^{2}$ and Seong-Ho Choi ${ }^{1}$ \\ ${ }^{1}$ Department of Chemistry, Hannam University, Daejeon 305-811, Republic of Korea \\ ${ }^{2}$ Division of Metrology for Quality of Life, Korea Research Institute of Standards and Science, Daejeon 305-600, Republic of Korea
}

Correspondence should be addressed to Seong-Ho Choi, shchoi@hnu.kr

Received 26 January 2012; Revised 28 March 2012; Accepted 28 March 2012

Academic Editor: Sevan P. Davtyan

Copyright () 2012 Yu-Jin Lee et al. This is an open access article distributed under the Creative Commons Attribution License, which permits unrestricted use, distribution, and reproduction in any medium, provided the original work is properly cited.

\begin{abstract}
A biosensor comprising tyrosinase immobilized on bifunctionalized multiwalled carbon nanotube (MWNT) supports was prepared for the detection of phenolic compounds in drinks such as red wine and juices. The MWNT supports were prepared by radiation-induced graft polymerization (RIGP) of epoxy-containing glycidyl methacrylate (GMA), to covalently immobilize the tyrosinase, and vinyl ferrocene (VF), which can act as an electron transfer mediator via redox reactions. The bifunctionalized MWNTs were characterized by X-ray photoelectron spectroscopy (XPS), transmission electron microscopy (TEM), and thermogravimetric analysis (TGA). Electrodes prepared with the MWNTs showed increased current with increasing VF content. A biosensor comprising tyrosinase immobilized on the bifunctionalized MWNTs could detect phenol at 0.1-20 mM. Phenolics in red wine and juices were determined using the biosensor after its calibration.
\end{abstract}

\section{Introduction}

Amperometric enzymatic biosensors are potentially useful in chemical and biomedical analyses, pollution monitoring, biotechnology, and food and agricultural processing [1-3]. They are suitable for biochemical analysis because of their good selectivity, sensitivity, rapid responses, compactness, and reproducible results $[4,5]$. However, the electron transfer efficiency of the redox enzymes is poor in the absence of mediator, because the enzymes' active sites are deeply embedded in the protein. Biosensors' sensitivities can be significantly improved by the addition of mediators in the sensors' matrices.

Ferrocene and its derivatives have been reported as electron transfer mediators due to their relatively low molecular mass, reversibility, regeneration at low potential, and generation of stable redox forms [6-9]. There has been much research on of the immobilization of electron transfer mediators on electrodes' surfaces, because low-molecularweight, soluble mediators can easily diffuse away from an electrode's surface into the electrolyte if a biosensor is used continuously, significantly decreasing the electron signal and the performance and lifetime of the biosensor. The covalent immobilization of ferrocene derivatives onto electrode supports can reduce this problem.

Radiation-induced graft polymerization can introduce specific characteristics to the surface of a functional polymer's matrix such as thermal stability, mechanical strength, electronic properties, and crystallinity. Enzymatic biosensors have been prepared by the radiation-induced graft polymerization of vinyl monomers with various functional groups onto MWNTs at room temperature [10-14]. The functional groups of the vinyl monomers can be used as physical interaction sites because they have hydrophilic properties compatible with those of the enzyme, allowing their functional groups to interact easily on the surface of the electrode. MWNTs have been used as supporting materials because of their high chemical stability, high surface area, unique electronic properties, and relatively strong mechanical properties [15].

Glycidyl methacrylate (GMA) is a monomer that can be easily modified with various functional groups. As it 

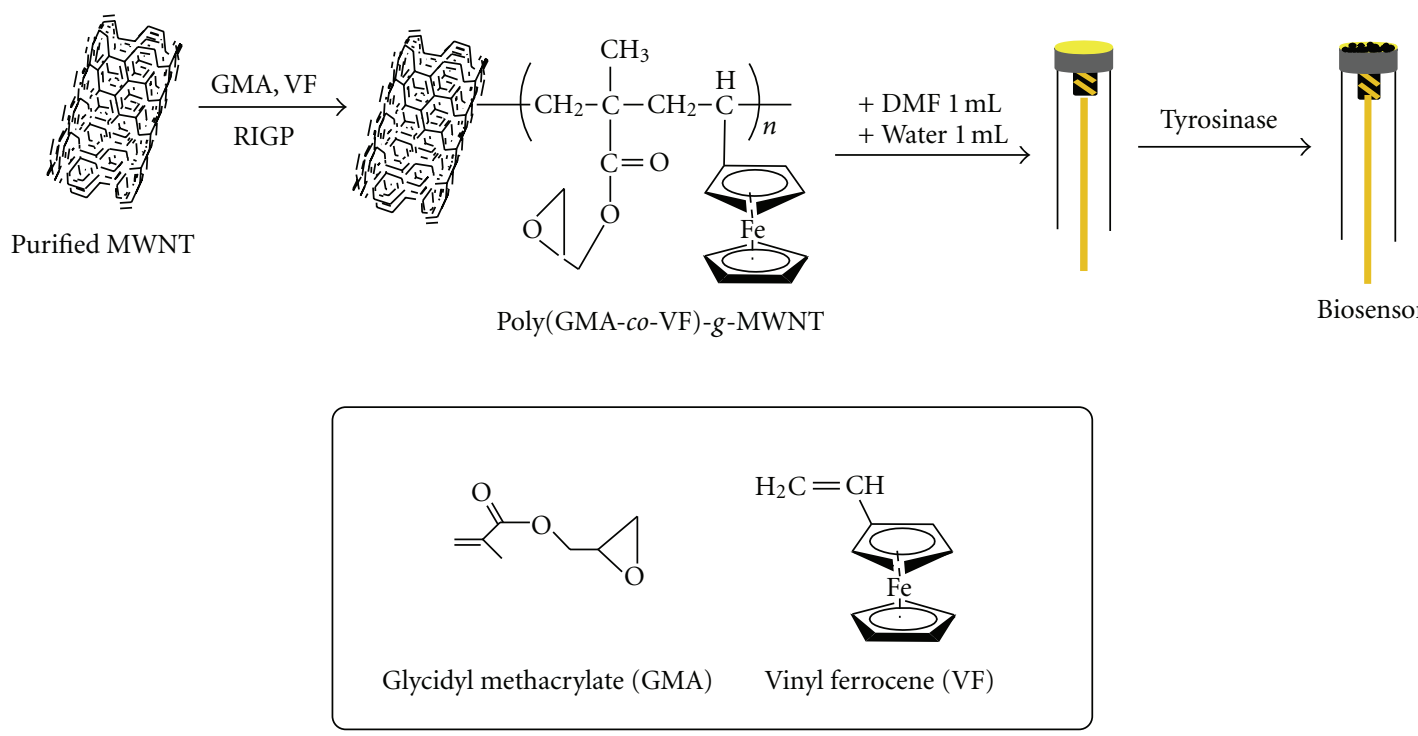

Figure 1: Preparation tyrosinase-immobilized biosensor on MWNT supports for the detection of phenolic compounds.

is polymerized, its epoxy groups become available for the introduction of functional groups, such as amines [16], alcohols [17], phosphoric acid [18], and proteins [19, 20]. The epoxy-modified polymer surface is stable over long storage periods and is relatively resistant to hydrolysis. Biomolecules, such as proteins, can be covalently coupled by opening the epoxide bridges in alkaline media.

On the other hand, the biosensors based on MWNT for determination of phenolic compounds have been studied by many researchers [4, 21-23]. However, there are no reports about the preparation of MWNTs supporting with bifunctional group using radiation-induced graft polymerization until now.

This work reports MWNT supports with epoxy groups, as covalent sites, and ferrocene groups, as electron mediators, prepared by RIGP with various composition of GMA and VF monomers. The resulting MWNT supports were analyzed by X-ray photoelectron spectroscopy (XPS), transmission electron microscopy (TEM), and thermogravimetric analysis (TGA). Electrodes were prepared by hand casting the MWNT supports onto the surface of GC electrodes. Their currents were measured with respect to the relative composition of the GMA and VF monomers. A tyrosinaseimmobilized biosensor was prepared by immobilizing tyrosinase in $0.1 \mathrm{M}$ carbonated buffer solution $(1.0 \mathrm{~mL}, \mathrm{pH} 9.5)$ for the detection of phenolic compounds. Its phenol sensing efficiency was evaluated in a phosphate buffer solution. Optimal operating conditions such as $\mathrm{pH}$, temperature, and phenol detection range were evaluated. Total phenolic concentrations in three red wines and twelve juices were then determined using the tyrosinase-modified biosensor.

\section{Experiment Details}

2.1. Reagents. Tyrosinase from mushrooms (EC 1.14.18.1), phenol, p-chresol, catechol, glycidyl methacrylate (GMA), and vinyl ferrocene (VF) were from Aldrich-Sigma Chemical Co., MWNTs (CM-95) were from Hanwha Nanotech Co., Ltd., (Republic of Korea). Solutions were prepared with water from a Milli-Q puls water purification system (Millipore Co., Ltd., final resistance, $18.2 \mathrm{M} \Omega \mathrm{cm}^{-1}$ ) that was degassed prior to each measurement. Other chemicals were of reagent grade.

2.2. Preparation of a Biosensor Comprising Tyrosinase Immobilized on Bifunctionalized MWNT Supports. Figure 1 outlines the preparation of the tyrosinase-immobilized phenol biosensor. The MWNTs were first purified to remove the catalyst and noncrystallized carbon impurities by treatment with phosphate solution. They were then used as the supporting material for grafting binary vinyl monomers: GMA, with epoxy groups, and VF, which can act as an electron transfer mediator via rodox reactions. $0.2 \mathrm{~g}$ MWNT and various compositions of the binary vinyl monomers (Table 1) were mixed in methanol $(350 \mathrm{~mL})$. Nitrogen gas was bubbled through the solution for $30 \mathrm{~min}$ to remove oxygen. The solution was then irradiated by $\gamma$-rays from a ${ }^{60} \mathrm{Co}$ source under atmospheric pressure and ambient temperature. $30 \mathrm{kGy}$ was administered at $1.0 \times 10^{4} \mathrm{~Gy} / \mathrm{h}$. The prepared MWNT supports were dried in a vacuum oven at $50^{\circ} \mathrm{C}$, and $3.0 \mathrm{mg}$ was then dissolved in a mixture of DMF $(1.0 \mathrm{~mL})$ and water $(1.0 \mathrm{~mL})$ to prepare the coating solution. MWNT electrodes were fabricated by hand casting $6.0 \mu \mathrm{L}$ coating solution onto GC electrodes $(0.2 \times 0.2 \mathrm{~cm})$ and drying in a vacuum oven at $50^{\circ} \mathrm{C}$ for $24 \mathrm{hrs}$. Tyrosinase was covalently immobilized on the epoxy groups of the most suitable MWNT electrode by immersing the electrode in $0.1 \mathrm{M}$ carbonated buffer solution $(1.0 \mathrm{~mL}, \mathrm{pH}=9.5) .1 .0 \mathrm{~mL}$ base tyrosinase solution was then added to the MWNT electrode in $0.1 \mathrm{M}$ carbonated buffer solution, and the reaction solution was adjusted to $\mathrm{pH} 9.0$ with $0.1 \mathrm{M} \mathrm{NaOH}$. Tyrosinase was immobilized on the electrode by incubation with shaking at $37^{\circ} \mathrm{C}$ for $20 \mathrm{~h}$. The tyrosinase-immobilized 
TABLE 1: Properties of the MWNT supports with bifunctional group prepared by RIGPa .

\begin{tabular}{cccccc}
\hline No & Feed & Graft yield $(\%)^{\mathrm{b}}$ & Fe content $(\%)^{\mathrm{c}}$ & CV current $(\mathrm{mA})$ \\
\hline 1 & GMA (mol-\%) & VF (mol-\%) & 20.0 & - & $2.27 \times 10^{-4}$ \\
2 & 100 & 0 & 30.0 & 0.24 & $5.60 \times 10^{-2}$ \\
3 & 80 & 20 & 15.0 & 0.36 & 0.31 \\
4 & 60 & 60 & 20.0 & 0.36 & $1.21 \times 10^{-2}$ \\
5 & 40 & 80 & 20.0 & 0.47 & $1.09 \times 10^{-1}$ \\
6 & 20 & 100 & 25.0 & $1.33 \times 10^{-2}$ \\
\hline
\end{tabular}

${ }^{\mathrm{a}}$ Reaction condition: MWNT $0.2 \mathrm{~g}$, solvent $350 \mathrm{~mL}(\mathrm{MeOH})$.

${ }^{b}$ Determined by TGA. ${ }^{c}$ Determined by XPS.

biosensor was rinsed six times with $0.1 \mathrm{M}$ carbonated buffer ( $\mathrm{pH}$ 8.0) and then twice with acetic acid buffer solution ( $\mathrm{pH}$ 4.0). The resulting biosensor was stored in phosphate buffer ( $\mathrm{pH} 7.0)$.

\subsection{Determination of Phenolic Compounds in Drinks using} Tyrosinase-Modified Biosensor. Total concentration of the phenolic compounds for drinks was determined by comparison of calibration curves (see Figure 6). In detail, the drop of drinks $(0.04 \mathrm{~mL})$ was added in PBS solution $(\mathrm{pH} 7.0$, $3.96 \mathrm{~mL}$ ), and then the cyclic voltammograms for phenolic compounds using the prepared biosensor were recorded.

2.4. Instrumentation. Cyclic voltammograms were measured with a potentiostat/galvanostat (model 283. Ametek PAR, USA) in a conventional three-electrode system. The working electrode was the GC MWNT electrode, the counterelectrode was platinum wire, and the reference electrode was $\mathrm{Ag} / \mathrm{AgCl}$ (sat'd $\mathrm{KCl}$ ). Samples' surface morphologies were determined by HR-TEM (JEOL, JEM-2010, USA). X-ray photoelectron spectra were measured using on a MultiLab ESCA2000 (Thermo Fisher Scientific). Thermal gravimetric analysis (TGA) was conducted on a Scinco TGA S-1000 (Seoul, Republic of Korea) under $\mathrm{N}_{2}$ flow from $25^{\circ} \mathrm{C}$ to $700^{\circ} \mathrm{C}$ at a heating rate of $20^{\circ} \mathrm{C} / \mathrm{min}$.

\section{Results and Discussion}

3.1. Preparation and Characterization of MWNT Supports with Bifunctional Groups. Various vinyl monomers such as acrylic acid, methacrylic acid, glycidyl methacrylate, maleic anhydride, and vinylphenyl boronic acid have previously been grafted onto MWNT surfaces by radiation-induced graft polymerization in aqueous solutions at room temperature [15]. Vinyl monomers were selected for this work because they possess hydrophobic sites to complement the hydrophilic functional groups attached to them. The vinyl groups interacted with the MWNTs' surfaces through hydrophobic-hydrophobic interactions, and the functional groups attached to the vinyl monomers interacted with the aqueous solution through their hydrophilic properties. Radical polymerization of the vinyl monomers was performed on the surfaces of the MWNTs during $\gamma$-irradiation. This successfully introduced various functional groups to the MWNTs' surface while maintaining their tubular morphology. Tyrosinase-immobilized biosensors incorporating MWNT supports with anion-exchange [11], hydroxy [12], and carboxylic acid [13] groups for the detection of phenolic compounds have been prepared by the physical adsorption of tyrosinase onto the MWNTs by RIGP. Biosensors prepared by physical adsorption are of limited use as the adsorbed tyrosinase can dissociate into the electrolyte during sensing, greatly reducing sensing efficiency. To overcome enzyme dissociation from the electrode, the tyrosinase should be covalently immobilized on the surface of the MWNT electrode. Therefore, GMA was chosen here to form covalent bonds between its epoxy groups and amine groups of the tyrosinase in alkali medium. Vinyl ferrocene, with ferrocene groups, was selected as an electron transfer mediator to increase sensing efficiency via redox reactions for the detection of phenolic compounds.

Table 1 lists the results of radiation-induced graft polymerization of various compositions of GMA and VF onto the MWNTs in $\mathrm{MeOH}$ at room temperature. Grafting yields were found to be $15-30 \%$ by TGA. Fe contents increased with increasing VF content. The maximum CV current was displayed by the electrode with a molar ratio of GMA/VF of 80/20 (sample 5 in Table 1).

Figure 2 shows TEM images of the purified MWNTs, and sample 5 prepared by RIGP. A fine coating on the surfaces of MWNTs that increased their diameter (from $21 \pm 0.05 \mathrm{~nm}$ to $34 \pm 0.05 \mathrm{~nm}$ ) is observable in sample 5 . The increased diameter of the MWNTs indicates the successful attachment of bifunctional groups by the radiation graft polymerization. These MWNT supports can be covalently immobilized with biomolecules such as enzymes, microbial molecules, and proteins through reactions of epoxy group of the functionalized MWNTs and amine groups of the biomolecules in alkali medium.

Figure 3 shows XPS spectra of the pure and RIGP-functionalized MWNTs. Grafting the monomers significantly affected the XPS data. The characteristic Fe 2ps peak at $713 \mathrm{eV}$ appeared after grafting. Grafting with GMA resulted in an additional peak at $288.7-289.5 \mathrm{eV}$ due to carbonyl groups in the polymer chains. These data support the successful functionalization of the MWNTs by RIGP.

Figure 4 shows TGA curves of the purified and functionalized MWNTs prepared by one-step radiation-induced graft 


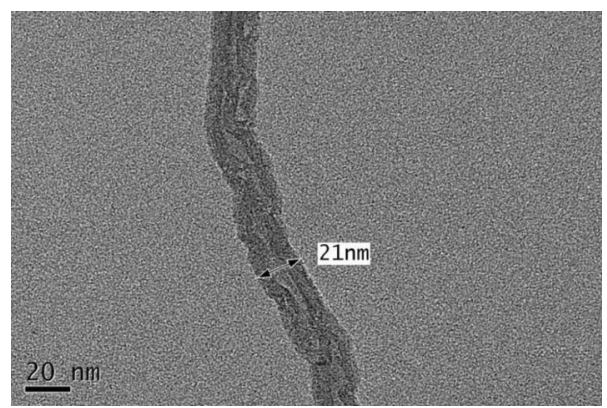

(a)

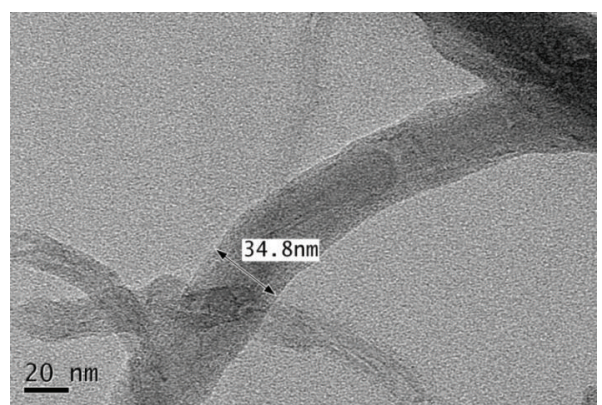

(b)

FigurE 2: TEM images of (a) purified MWNTs and (b) sample 5 in Table 1.
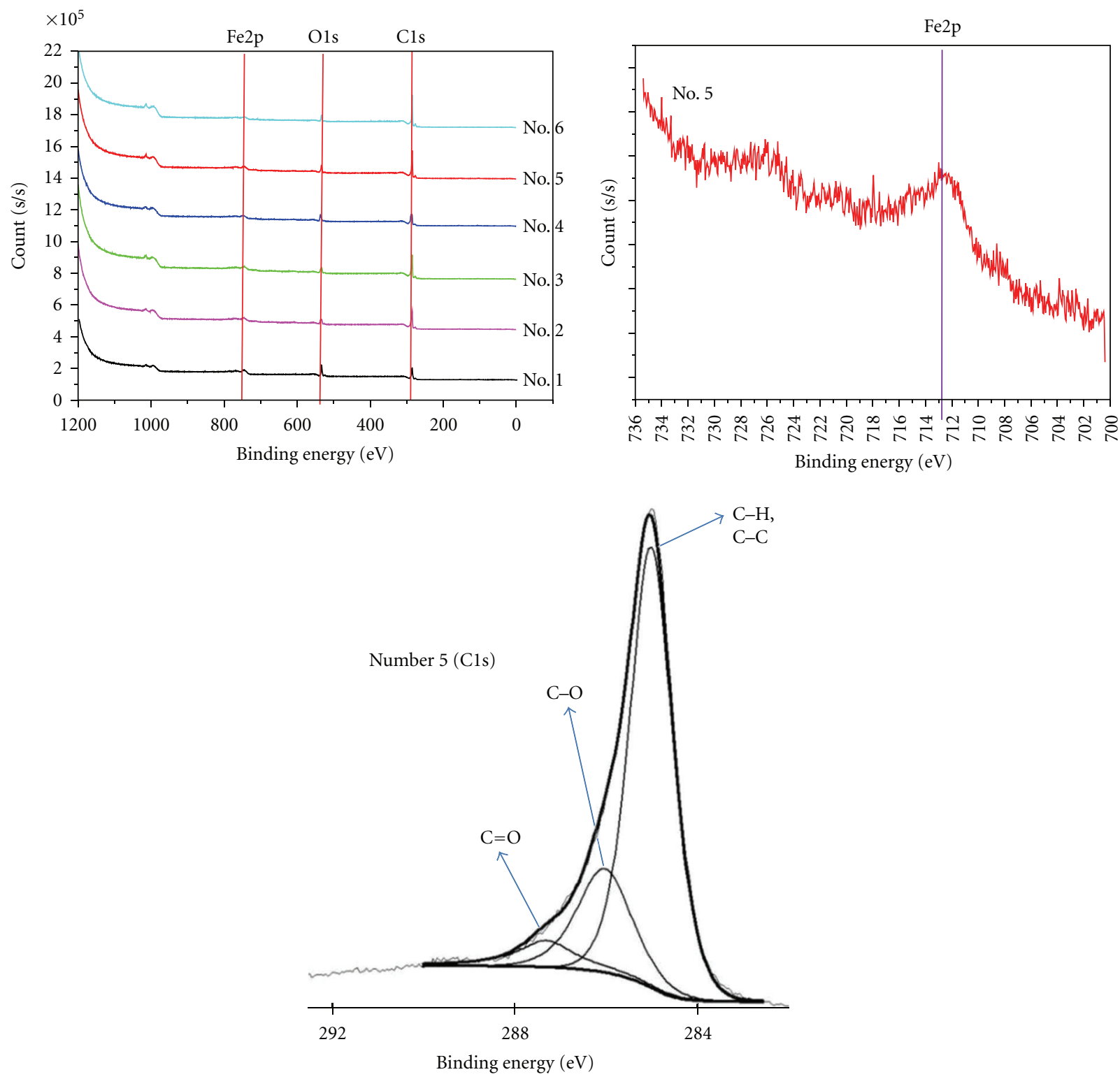

FIgURE 3: XPS spectra of the MWNT supports in Table 1. 


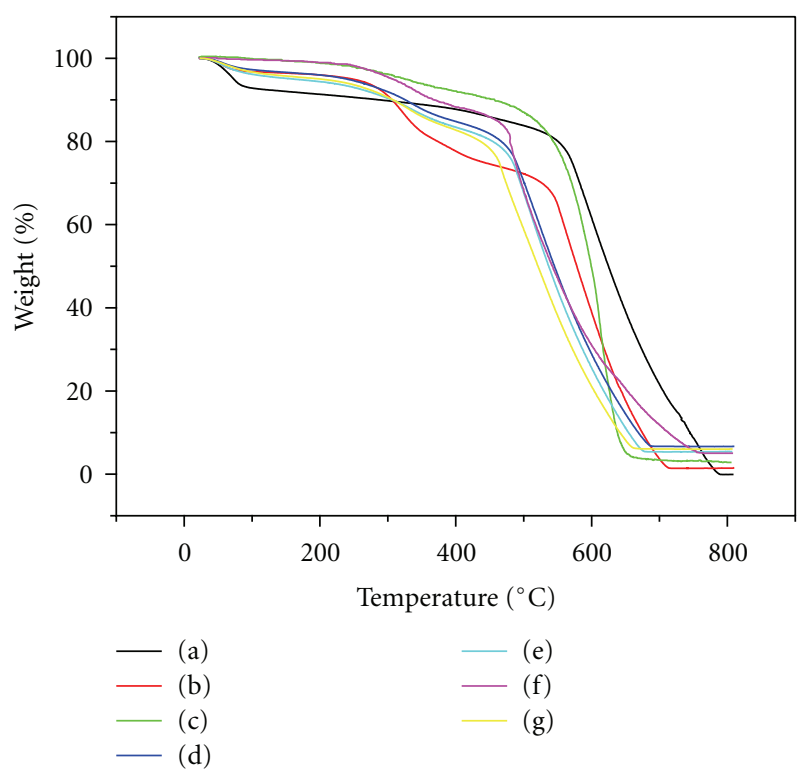

Figure 4: TGA curves of (a) purified MWNTs and samples in Table 1: (b) 1, (c) 2, (d) 3, (e) 4, (f) 5, and (g) 6 .

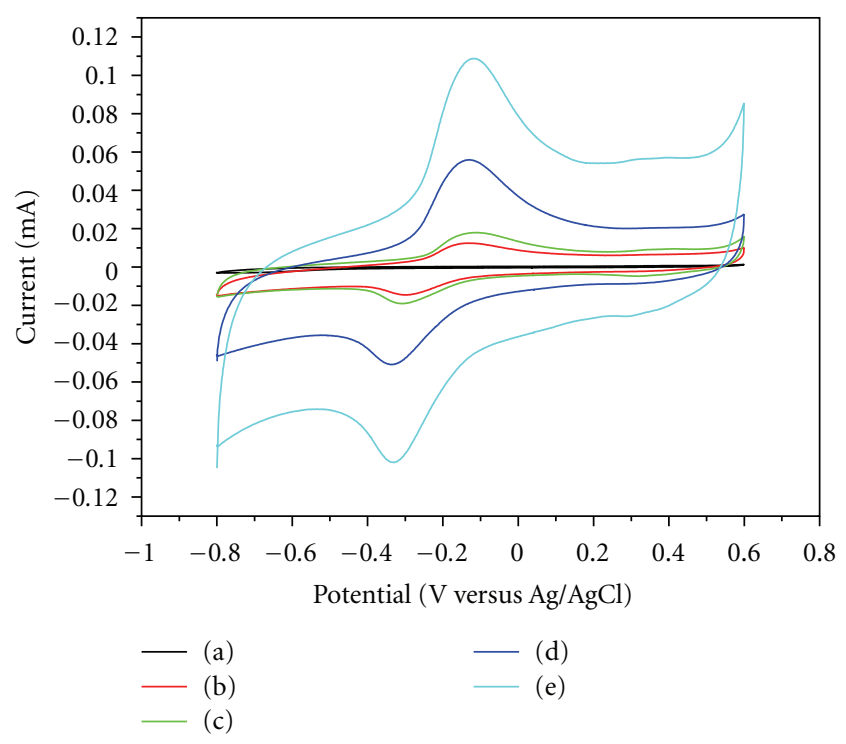

FIgURe 5: Cyclic voltammograms in PBS at pH 7.0 of (a) GCE and samples in Table 1: (b) 2, (c) 3, (d) 4, and (e) 5.

polymerization. The first weight loss from $50^{\circ} \mathrm{C}$ to $250^{\circ} \mathrm{C}$ for the vinyl polymer-grafted MWNTs was attributable to moisture loss because of the hydrophilic properties of the grafted vinyl polymers. The second weight loss at $250-600^{\circ} \mathrm{C}$ was due to weight loss through the grafted vinyl polymer. These results show that graft yields were $c a .15 .0-30.0 \%$ after RIGP of vinyl monomers.

To coat MWNT supports onto GC electrodes, polymer binder is generally used. However, the functionalized MWNT supports prepared here possessed polymer surfaces and could be coated onto the surfaces of GC electrodes using a DMF/water mixture without polymer binder. After hand casting the MWNTs onto GC electrodes' surfaces, CV data were recorded in PBS at pH 7.0 (Figure 5). The current increased with increasing Fe content of the binary monomer mixture (Table 1). The maximum current was detected on the electrode prepared with sample 5 in Table 1 , which was therefore expected to have the best sensing efficiency.

Table 2 exhibits the comparison of the electrochemical properties to the tyrosinase-modified biosensors. The biosensor prepared in this study has a good stability and sensitivity compared to that of other biosensor because of covalently bonding and presence of electron transfer mediator onto electrode supports, respectively. As results, the radiation-induced copolymerization of two functional monomers was good method for preparation of biosensorsupporting materials.

3.2. Determination of Phenolic Compounds in Drinks Using a MWNT-Based Biosensor. Biosensors comprising tyrosinase immobilized on MWNT supports have been prepared through the physical adsorption of tyrosinase onto electrodes supporting MWNTs with hydrophilic functional groups [1113]. However, such electrodes are of limited use because the enzyme can desorb into the electrolyte during detection. Therefore, a covalently immobilized tyrosinase-based biosensor was prepared here.

Cyclic voltammograms of phenols on the biosensor were recorded in $50 \mathrm{mM}$ phosphate buffer at $\mathrm{pH} 7.0$ as a function of phenol concentration (Figure 6). The detection response range for phenol was found to be $0.1-20 \mathrm{mM}$. The sensitivity of the biosensor was $0.187 \mathrm{~A} \mathrm{M}^{-1} \mathrm{~cm}^{-2}$.

Total phenolics in red wine samples detected in a phosphate buffer using the tyrosinase-immobilized biosensor at room temperature were found to be in the range of 580$913 \mathrm{mg} / \mathrm{L}$ as shown in Table 3.

Total phenolic of several juices were also measured in PBS using the tyrosinase-immobilized biosensor at room temperature; they ranged between 490 and $750 \mathrm{mg} / \mathrm{L}$ (Tables 4 and 5). These tests demonstrate the effectiveness of the prepared tyrosinase-immobilized biosensor for the determination of phenolic compounds in drinks.

\section{Conclusion}

A covalently immobilized tyrosinase-based biosensor was fabricated on MWNT supports bifunctionalized by radiation-induced graft polymerization. Its sensing range for phenol was $0.1 \mathrm{mM}-20 \mathrm{mM}$. It was used to determine phenolic compounds in commercial red wines and juices in phosphate buffer solution; it found $580-913 \mathrm{mg} / \mathrm{L}$ phenolics in various red wines and $490-750 \mathrm{mg} / \mathrm{L}$ phenolics various juices. These results were calculated from a calibration curve of phenols compiled for the sensor. These results show that bifunctionalized MWNT supports can be used in enzymeimmobilized biosensors as good electron transfer materials and as supports for enzyme immobilization. 


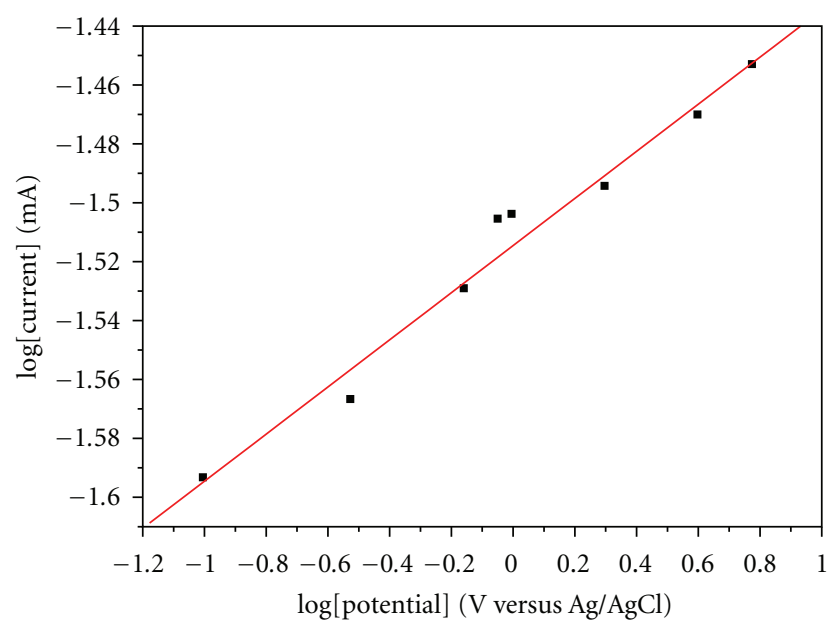

(a)

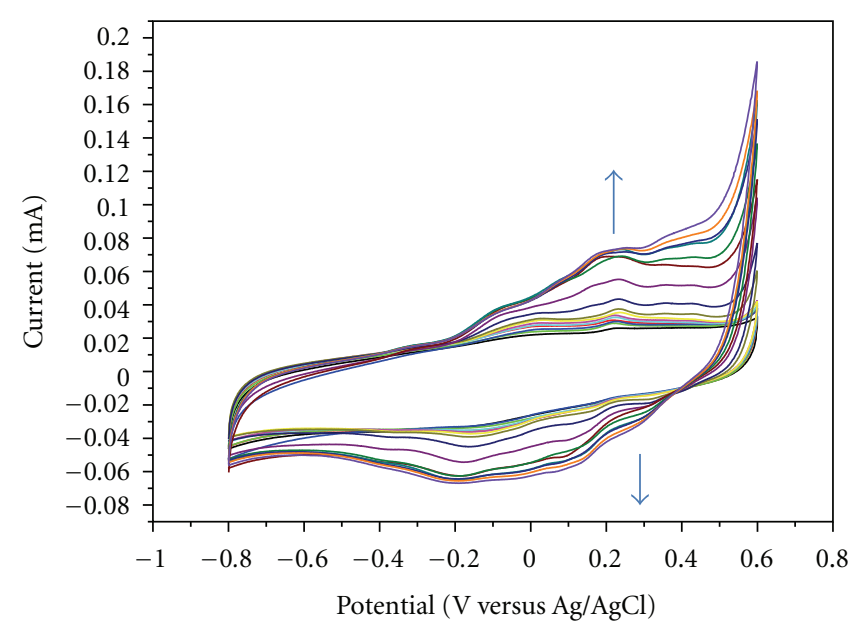

(b)

Figure 6: (a) Calibration curve and (b) CV curves of the tyrosinase-immobilized biosensor in PBS at pH 7.0 with $0.1 \mathrm{mM}-20 \mathrm{mM}$ phenol at a scan rate $50 \mathrm{mV} / \mathrm{s}$.

TABLE 2: Comparison of electrochemical properties to the tyrosinase-modified biosensors.

\begin{tabular}{|c|c|c|c|c|c|}
\hline Type of electrode & $\begin{array}{c}\text { Sensitivity } \\
\left(\mathrm{Am} \mathrm{M}^{-1} \mathrm{~cm}^{-2}\right)\end{array}$ & Sensing range & $\begin{array}{c}\text { Detection } \\
\text { limit }(n M) \\
\end{array}$ & Stability & Reference \\
\hline $\begin{array}{l}\text { Poly } 3,4 \text {-ethylenedioxythiophene/tyrosinase } \\
\text { electrode }\end{array}$ & 608 & Not reported & 5 & $\begin{array}{l}\text { Retains activity } \\
30 \% \text { after } 12 \text { days }\end{array}$ & {$[24]$} \\
\hline $\begin{array}{l}\text { Colloidal gold } \\
\text { nanoparticles/graphite-Teflon/tyrosinase }\end{array}$ & 407.04 & $0.010-8.0 \mathrm{M}$ & 20 & 39 days & {$[25]$} \\
\hline $\begin{array}{l}\text { Tyrosinase/3-mercaptopropionicacid-modified Au } \\
\text { electrodes }\end{array}$ & 196.7 & $0.2-100 \mathrm{M}$ & 88 & 5 days & {$[26]$} \\
\hline Organoclay-enzyme film electrodes & 75 & $0.2-15 \mathrm{M}$ & Not reported & Not reported & {$[27]$} \\
\hline Sol-gel immobilized tyrosinase electrode & 208.83 & $1-60 \mathrm{M}$ & 200 & $\begin{array}{l}\text { Retains activity } \\
57 \% \text { of after } 2 \\
\text { weeks }\end{array}$ & {$[28]$} \\
\hline Nafion/ZnO/tyrosinase films & 30.3 & $0.01-0.4 \mathrm{mM}$ & 4000 & $\begin{array}{l}\text { Retains activity } \\
81.2 \% \text { after } 20 \text { days }\end{array}$ & {$[29]$} \\
\hline $\begin{array}{l}\text { Poly(GMA-co-VF)-g-MWNT/DMF/tyrosinase } \\
\text { electrode }\end{array}$ & 187 & $0.1-20 \mathrm{mM}$ & 25 & $\begin{array}{l}\text { Retain activity } 90 \% \\
\text { after } 30 \text { days }\end{array}$ & This work \\
\hline
\end{tabular}

TABLE 3: Determination of the phenolic compound concentration in real sample using tyrosinase-immobilized biosensor based on MWNT supports with bifunctional group.

\begin{tabular}{lccc}
\hline Number & Brand name & Current (mA) & Phenolic compounds (mg/L) \\
\hline 1 & Cambras (France) & $3.89 \times 10^{-2}$ & 913 \\
2 & Demeter (Australa) & $4.11 \times 10^{-2}$ & 880 \\
3 & Jinro wine (Korea) & & \\
\hline \hline & & & \\
& & &
\end{tabular}


TABLE 4: Determination of the phenolic compounds concentration in real sample using tyrosinase-immobilized biosensor based on MWNT supports with bifunctional group.

\begin{tabular}{lccc}
\hline Number & Brand name & Current $(\mathrm{mA})$ & Phenolic compounds (mg/L) \\
\hline 1 & Haruyachae-Red & $9.96 \times 10^{-2}$ & 490 \\
2 & Haruyachae-Purple & $8.93 \times 10^{-2}$ & 527 \\
3 & Haruyachae-Yellow & $5.43 \times 10^{-2}$ & 732 \\
4 & Haruyachae-A & $5.99 \times 10^{-2}$ & 686 \\
5 & Haruyachae-B & $5.75 \times 10^{-2}$ & 705 \\
6 & Haruyachae-C & $5.75 \times 10^{-2}$ & 705 \\
\hline \multirow{2}{*}{} & & &
\end{tabular}

TABLE 5: Determination of the phenolic compounds concentration in real sample using tyrosinase-immobilized biosensor based on MWNT supports with bifunctional group.

\begin{tabular}{lccc}
\hline Number & Brand name & Current (mA) & Phenolic compounds (mg/L) \\
\hline 7 & Pulmuone yuki myung il yeok nok Jeub & $9.37 \times 10^{-2}$ & 510 \\
8 & Pulmuone yuki keil nok Jeub & $5.40 \times 10^{-2}$ & 735 \\
9 & Pulmuone danggeun Jeub & $6.18 \times 10^{-2}$ & 672 \\
10 & Namyang at Home orange juice & $7.81 \times 10^{-2}$ & 575 \\
11 & Seoulmilk 365 yuki achimtomato & $6.12 \times 10^{-2}$ & 676 \\
12 & Nongshim welchs grape juice & $7.61 \times 10^{-2}$ & 585 \\
\hline
\end{tabular}

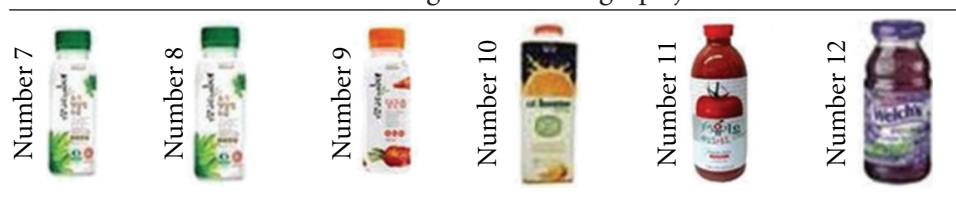

\section{Acknowledgment}

This work was supported by a National Research Foundation of Korea Grant funded by the Korean Government (20110010853).

\section{References}

[1] J. Wang, "Carbon-nanotube based electrochemical biosensors: a review," Electroanalysis, vol. 17, no. 1, pp. 7-14, 2005.

[2] M. I. Prodromidis and M. I. Karayannis, "Enzyme based amperometric biosensors for food analysis," Electroanalysis, vol. 14, no. 4, pp. 241-261, 2002.

[3] J. Wang, "Electrochemical glucose biosensors," Chemical Reviews, vol. 108, no. 2, pp. 814-825, 2008.

[4] Y. C. Tsai and C. C. Chiu, "Amperometric biosensors based on multiwalled carbon nanotube-Nafion-tyrosinase nanobiocomposites for the determination of phenolic compounds," Sensors and Actuators B, vol. 125, no. 1, pp. 10-16, 2007.

[5] Z. B. Zhang, S. J. Yuan, X. L. Zhu, K. G. Neoh, and E. T. Kang, "Enzyme-mediated amperometric biosensors prepared via successive surface-initiated atom-transfer radical polymerization," Biosensors and Bioelectronics, vol. 25, no. 5, pp. 1102$1108,2010$.

[6] A. E. G. Cass, G. Davis, G. D. Francis et al., "Ferrocenemediated enzyme electrode for amperometric determination of glucose," Analytical Chemistry, vol. 56, no. 4, pp. 667-671, 1984.
[7] A. Escorcia and A. A. Dhirani, "Electrochemical properties of ferrocenylalkane dithiol-gold nanoparticle films prepared by layer-by-layer self-assembly," Journal of Electroanalytical Chemistry, vol. 601, no. 1-2, pp. 260-268, 2007.

[8] S. F. Wang and D. Du, "Differential pulse voltammetry determination of ascorbic acid with ferrocene-1-cysteine selfassembled supramolecular film modified electrode," Sensors and Actuators B, vol. 97, no. 2-3, pp. 373-378, 2004.

[9] J. D. Qiu, W. M. Zhou, J. Guo, R. Wang, and R. P. Liang, "Amperometric sensor based on ferrocene-modified multiwalled carbon nanotube nanocomposites as electron mediator for the determination of glucose," Analytical Biochemistry, vol. 385, no. 2, pp. 264-269, 2009.

[10] M. H. Piao, D. S. Yang, K. R. Yoon, S. H. Lee, and S. H. Choi, "Development of an electrogenerated chemiluminescence biosensor using carboxylic acid-functionalized MWCNT and Au nanoparticles," Sensors, vol. 9, no. 3, pp. 1662-1677, 2009.

[11] K. I. Kim, H. Y. Kang, J. C. Lee, and S. H. Choi, "Fabrication of a multi-walled nanotube (MWNT) ionic liquid electrode and its application for sensing phenolics in red wines," Sensors, vol. 9, no. 9, pp. 6701-6714, 2009.

[12] J. H. Yang, J. C. Lee, and S. H. Choi, “Tyrosinase-immobilized biosensor based on the functionalized hydroxyl groupMWNT and detection of phenolic compounds in red wines," Journa of Sensors, vol. 2009, Article ID 916515, 9 pages, 2009.

[13] K. I. Kim, J. C. Lee, K. Robards, and S. H. Choi, "Immobilization of tyrosinase in carboxylic and carbonyl group-modified MWNT electrode and its application for sensing phenolics in 
red wines," Journal of Nanoscience and Nanotechnology, vol. 10, pp. 3790-3798, 2010.

[14] S. K. Kim, H. D. Kwen, and S. H. Choi, "Fabrication of a microbial biosensor based on QD-MWNT supports by a onestep radiation reaction and detection of phenolic compounds in red wines," Sensors, vol. 11, no. 2, pp. 2001-2012, 2011.

[15] D. S. Yang, D. J. Jung, and S. H. Choi, "One-step functionalization of multi-walled carbon nanotubes by radiation-induced graft polymerization and their application as enzyme-free biosensors," Radiation Physics and Chemistry, vol. 79, no. 4, pp. 434-440, 2010.

[16] S. H. Choi, K. P. Lee, and J. G. Lee, "Adsorption behavior of urokinase by polypropylene film modified with amino acids as affinity groups," Microchemical Journal, vol. 68, no. 2-3, pp. 205-213, 2001.

[17] S. H. Choi, G. T. Kim, and Y. C. Nho, "Adsorption of $\mathrm{Co}^{2+}$ and $\mathrm{Cs}^{1+}$ by polyethylene membrane with iminodiacetic acid and sulfonic acid modified by radiation-induced graft copolymerization," Journal of Applied Polymer Science, vol. 71, no. 6, pp. 999-1006, 1999.

[18] G. S. Park, J. H. Chang, H. J. Kim, S. H. Choi, and Y. C. Nho, "Preparation of Polypropylene Fabric Containing Phosphoric Acid Groups by Radiation-Induced Graft Copolymerization, and Its Adsorption to $\mathrm{Pb}^{2+}, \mathrm{Cu}^{2+}$ and $\mathrm{Co}^{2+}$," Journal of Analytical Science \& Technology, vol. 7, p. 7, 1999.

[19] S. H. Choi, Y. M. Hwang, J. J. Ryoo et al., "Surface grafting of glycidyl methacrylate on silica gel and polyethylene beads," Electrophoresis, vol. 24, no. 18, pp. 3181-3186, 2003.

[20] S. H. Choi, K. P. Lee, and H. D. Kang, "Immobilization of lipase on a polymeric microsphere with an epoxy group prepared by radiation-induced polymerization," Journal of Applied Polymer Science, vol. 88, no. 5, pp. 1153-1161, 2003.

[21] L. Liu, F. Zhang, F. Xi, and X. Lin, "Highly sensitive biosensor based on bionanomultilayer with water-soluble multiwall carbon nanotubes for determination of phenolics," Biosensors and Bioelectronics, vol. 24, no. 2, pp. 306-312, 2008.

[22] Y. Tan, W. Deng, B. Ge, Q. Xie, J. Huang, and S. Yao, "Biofuel cell and phenolic biosensor based on acid-resistant laccaseglutaraldehyde functionalized chitosan-multiwalled carbon nanotubes nanocomposite film," Biosensors and Bioelectronics, vol. 24, no. 7, pp. 2225-2231, 2009.

[23] S. Chawla, R. Rawal, and C. S. Pundir, "Fabrication of polyphenol biosensor based on laccase immobilized on copper nanoparticles/chitosan/multiwalled carbon nanotubes/polyaniline-modified gold electrode," Journal of Biotechnology, vol. 156, no. 1, pp. 39-45, 2011.

[24] C. Védrine, S. Fabiano, and C. Tran-Minh, "Amperometric tyrosinase based biosensor using an electrogenerated polythiophene film as an entrapment support," Talanta, vol. 59, no. 3, pp. 535-544, 2003.

[25] V. Carralero, M. L. Mena, A. Gonzalez-Corties, P. YanezSedeno, and J. M. Pingarron, "Development of a high analytical performance-tyrosinase biosensor based on a composite graphite-Teflon electrode modified with gold nanoparticles," Biosensors and Bioelectronics, vol. 22, no. 5, pp. 730-736, 2006.

[26] S. Campuzano, B. Serra, M. Pedrero, F. J. Manuel de Villena, and J. M. Pingarron, "Amperometric flow injection determination of phenolic compounds at self-assembled monolayerbased tyrosinase biosensors," Analytica Chimica Acta, vol. 494, pp. 187-197, 2003.

[27] J. Kemmegne Mbouguen, E. Ngameni, and A. Walcarius, "Organoclay-enzyme film electrodes," Analytica Chimica Acta, vol. 578 , no. 2, pp. $145-155,2006$.
[28] B. Q. Wang and S. J. Dong, "Organic-phase enzyme electrode for phenolic determination based on a functionalized sol-gel composite," Journal of Electroanalytical Chemistry, vol. 487, no. 1, pp. 45-50, 2000.

[29] L. Y. Chen, B. X. Gu, G. P. Zhu, Y. F. Wu, S. Q. Liu, and C. X. $\mathrm{Xu}$, "Electrocatalytic behavior of tyrosinase on $\mathrm{ZnO}$ nanorod," Journal of Electroanalytical Chemistry, vol. 617, pp. 7-13, 2008. 

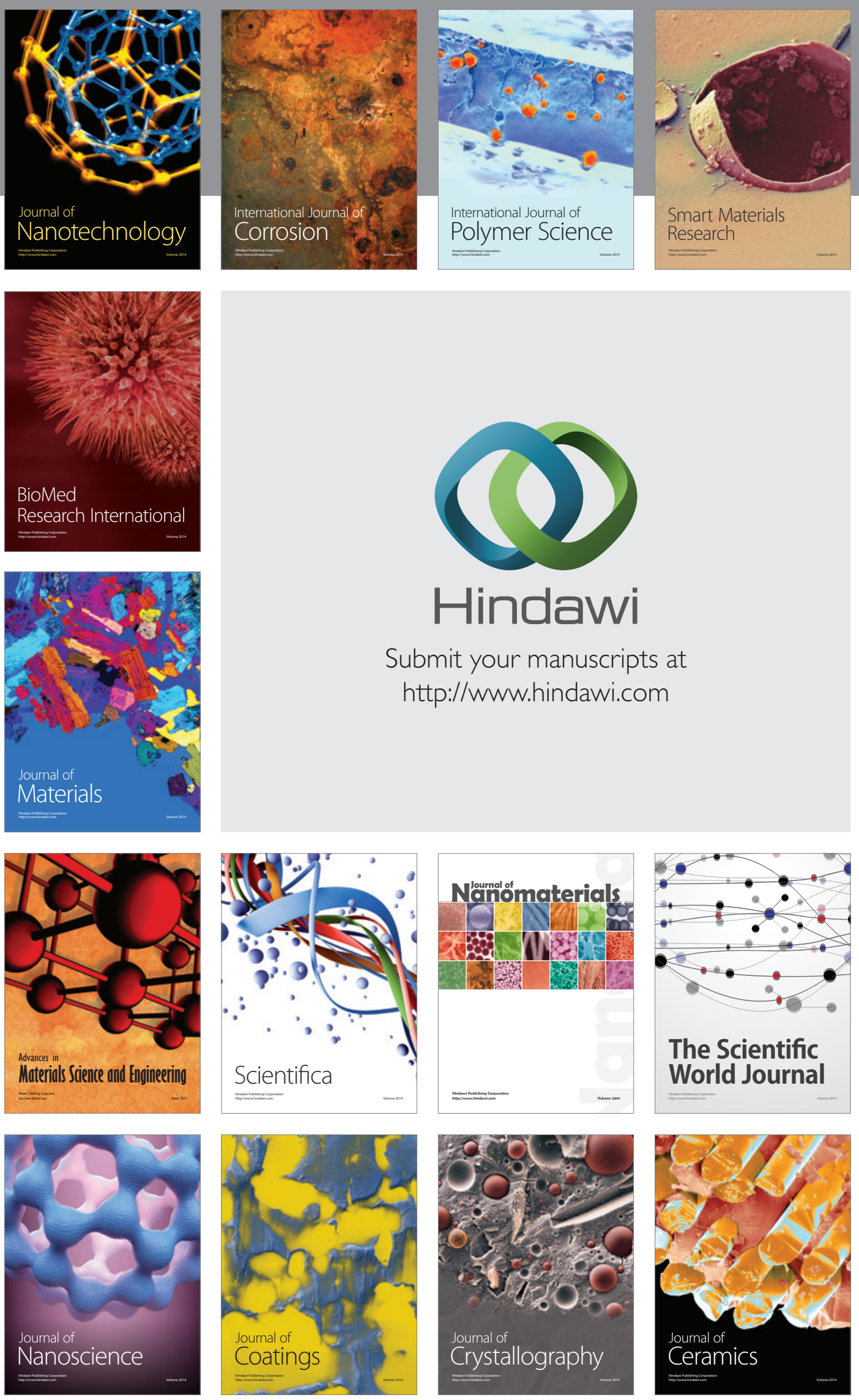

The Scientific World Journal

Submit your manuscripts at

http://www.hindawi.com

\section{World Journal}

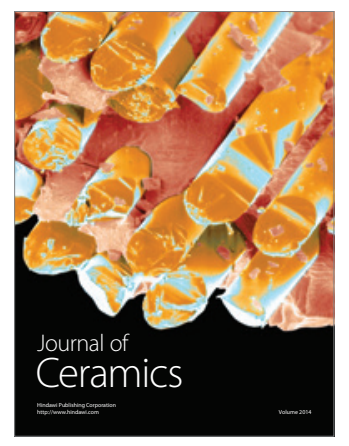

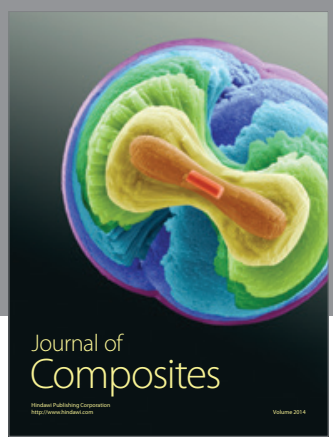
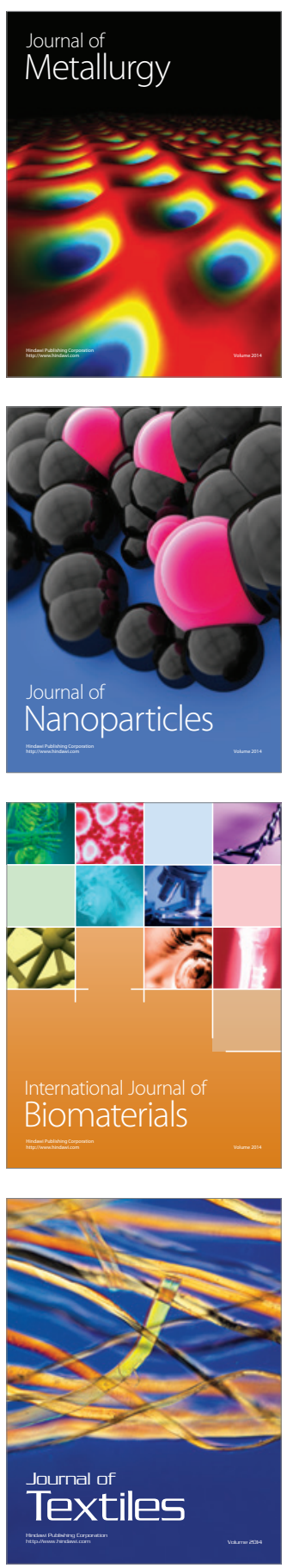